\title{
PATTERN OF ALCOHOL CONSUMPTION AND PSYCHOLOGICAL WELL-BEING AMONG COMMERCIAL BUS DRIVERS AND OKADA RIDERS IN IBADAN NIGERIA
}

\author{
A. Taiwo ${ }^{1}$, O. Atibioke ${ }^{2}$, E. Chinyio ${ }^{1}$ \\ ${ }^{1}$ University of Wolverhampton (UNITED KINGDOM) \\ ${ }^{2}$ University of Ibadan (NIGERIA) \\ a.taiwo@wlv.ac.uk,yemitibioke@gmail.com,e.chinyio@wlv.ac.uk
}

\begin{abstract}
Background: Traffic accidents contribute to injuries, deaths and disability globally, especially in developing countries. While most developed countries have data banks for effective road traffic planning, design and safety, there is a relative paucity of empirical studies in developing countries which especially concentrate on the personal factors and lifestyle of road users. As user-behaviour is an important element in road provision and sustenance, teaching and research ought to factor it in pedagogy.

Objectives: WHO (2009) crash statistics comparisons showed Nigeria as the country with the highest rate of fatal road traffic crashes (33.7 deaths per 100,000 population per year) in the world, with young men between the ages of $15-44$ constituting $62 \%$ of all deaths. Drunk-driving has been implicated as a major cause. An underlying study which examined the patterns of alcohol drinking and psychological wellbeing of commercial-drivers and motorbike-carriers in Ibadan metropolis in Nigeria was carried out to: demonstrate how adverse psychological states and drink-driving of road transport users can hamper efforts with road provision and safety; enhance a more holistic transportation policy; and, contribute to research informed-teaching.

Design of the underlying study: The study was mainly descriptive and adopted a cross-sectional survey design.

Method: 285 male volunteers were purposively sampled (consisting of 183 Commercial-drivers and 102 motorbike-carriers) and administered measures of socio-demographic factors, as well as the Eysenck Personality Inventory and Zung Self-rating Anxiety scale. Data was collected from the major (motor) parks across the city. The study followed all the necessary ethical procedures. Data were analysed by descriptive and inferential statistics.

Result: The Chi square analysis showed a significant relationship between the two groups of road transport users and frequency of drinks: $\left.X^{2}(8,285)=49.2 ; \mathrm{p}<.001\right)$. The trend showed that commercial-drivers consume unbranded alcohol more than the motorbike-carriers, but more motorbike-carriers tend to take mixtures of branded and unbranded alcohol than commercial drivers. There were significant inverse relationships between the participants' onset-age of alcohol consumption and their scores on the neuroticism and anxiety scales. However, a significant positive relationship was observed between depression and current age.

Impact of the findings on pedagogy: Indiscriminate consumption of various alcohol products is frequent among Nigerian commercial-road-transport-users and this affects their psychopathology. There is a need for the greater enforcement of drink limits and design of programmes that will target the psychological wellbeing of commercial road transport users in the Nigerian community. This, coupled with other road safety measures could enhance safety for other road users and commuters. A broader approach where the providers of infrastructures should understand the behavioural rationale of users and its impact on the facilities should extend to the classroom. This study therefore supports the researchers' concept of Psycon (Psychology in Construction) as a pedagogic initiative. Psycon aims to answer the questions: how can the teaching of behavioural issues be enhanced in construction?; how can cross-disciplinary research by scholars from psychology and construction improve the provision and use of public facilities like roads?
\end{abstract}

Keywords: Alcohol consumption, Anxiety, Commercial-drivers, Neuroticism, Okada-riders, Psychological wellbeing, Road safety. 


\subsection{INTRODUCTION}

Teaching should inform research and vice-versa. Pedagogy does influence research interests and often guides the paths and bounds of studies. Likewise research outcomes should feedback into learning and teaching and that way develop pedagogy. In this regard, a research which led to the reflective thinking on the pedagogic aspects of road design, provision and maintenance is reported. From this reflection, an initiative to foster greater synergy between construction and psychology in terms of pedagogy and research was launched. This paper therefore introduces the research and ends up by encouraging more collaboration between these two disciplines.

The burden of road traffic accidents leading to death, injury and disabilities is rising considerably [1], [2], [3]. It has been estimated that 1.2 million people die on the world's roads annually, and $85 \%$ of these deaths occur in low and middle income countries. Africa's road traffic injury and mortality has been ranked as the highest world-wide [4],[5]. The rate of road traffic injury and mortality in Africa stands at 32.2 per 100,000 compared with 13.4 per 100,000 in Europe. Effective road traffic planning, design and safety could mitigate this, but these have been previously regarded as purely engineering concerns. This is because the steps in transportation infrastructure which include planning, design, survey, construction, operations and maintenance, are all built within the pedagogy of transportation engineering.

The pedagogy in transport planning and engineering covers the remit of the design of systems which determines the nature of how people and goods are transported. The rise in road traffic accidents, deaths and injury despite new road innovations would suggest that there is need for additional inputs to improve road safety. [6] observed that a combination of the scientific study of human behaviour with engineering, epidemiology and other disciplines could create a better picture of comprehensive solutions to road traffic injury. This in itself suggests a multi-disciplinary approach to issues like road infrastructure. However, a systematic review has shown that applied behaviour and social science theory to road traffic injury remains scarce within published literature [7] with more recent literature showing no change to the situation [6].

One of the major countries most affected with road safety problems is Nigeria in Africa. Nigeria (with 33.7 deaths per 100,000 of the population per year) has the highest rate of fatal road traffic accidents in the world [4]. Young men between the ages of $15-44$ constitute $62 \%$ of all deaths. Nigeria is also among the six countries identified as priority for the drink-driving initiative [4]. Yet, deceptive ways of alcohol drinking before driving has been separately observed by previous studies in Nigeria as a significant threat to road safety among Commercial Drivers and Okada Riders [8], [9], [10], [11]. Commercial Drivers (CDs) transport passengers using 4-wheeled vehicles while Okada Riders (ORs) use two-wheeled motorcycles. The motor bike carriers are common in Nigeria especially around areas of the city where there are not many commercial buses or rural areas where the roads are bad. Sometimes, the motor bike carriers will be the choice of transportation for people as they believe it will aid their quick arrival to their destinations. Researchers have noted that the sale of both branded and unbranded beverage alcohol products at motor packs and mid-highway towns where drivers stop to rest and refresh themselves are serious contributory factors to drink-driving misdemeanours. However, no study has specifically examined how drink-driving in Nigeria relates with the psychological wellbeing of drivers to hamper road safety among these road users.

The psychological well-being of drivers has been previously studied in relation to crash risks among drivers [12]. A systematic review of 7 studies by [13] suggests a possible significant increase of the risk of accident amongst individuals with mood disorders and certain personality traits. Some previous studies have also indicated that a significant relationship seems to exist between anxiety disorders and depression, e.g. [14, [15], [16]. However a long time debate exists on this issue as some studies have reported no connection between anxiety and depression, e.g. [17], [18]. These studies emphasise the importance of personal factors in the understanding of crash risks and road safety. 
Although the current study will not clinically diagnose depression and anxiety, self-reported measures will be used to explore these factors among the participants.

The personality traits of interest in this study have been variously examined with different participants at various settings. Literature abounds of various studies that have examined Neuroticism, psychoticism and extraversion-introversion among people in various settings such as organisations, criminal justice system, education, hospital/health care settings, etc., e.g [19], [20). Previous studies have found 'Lie' as a trait for social desirability, social conformity and/or lack of self- insight tendency [21], [22], [23] and [24]. Neuroticism which implies traits of emotional instability may be found to relate with anxiety and depression among the participants and it might also be that it is related to drinkdriving behaviour.

As young men constitute the highest number of deaths in crash statistics, it might be important to examine how this relates to the psychological well-being and alcohol drinking among drivers in that age category. Moreover, a previous study by [25] reported an association between the age of the onset of alcohol consumption and subsequent continuous alcohol consumption and even alcohol dependency problems in adulthood. Another study by [26] showed that the early onset of alcohol use might be related to the presence of childhood depressive symptoms as the researchers found children with medium or high level of depressive symptoms twice more likely to use alcohol compared with those with less than two depressive symptoms. Thus the study being reported examined this factor within the data to see how the age of the onset of drinking relates with subsequent drinking pattern and depression.

\subsection{Objective}

This study examined the pattern of alcohol drinking and explored its relationship to psychological wellbeing, including personality traits and some demographic factors among the CDs and ORs in Ibadan, Nigeria. This information could be useful for informing road safety policies, as well as the design of psychological wellbeing enhancements and attitude change programmes for the commercial road users. The information could further create insight and understanding within the research and pedagogy of transport engineering and road safety management.

\subsection{METHODOLOGY}

\subsection{Design}

This quantitative study was a cross-sectional survey and adopted a correlational design. Ethical approval was obtained from the ethics committee of the Faculty of the social sciences of the University of Ibadan Nigeria. Permission was also obtained from the motor park gatekeepers (the National Union of Road Transport Workers' zonal leaders) before obtaining consent from the participants. The study questionnaire was administered to the participants: 1) early in the morning before they started their daily driving or 2) during their break times, or 3) in the evening; depending on what convenient time each driver or rider had chosen.

\subsection{Participants}

These included 183 commercial drivers and 102 Okada riders. All the participants were males since women are hardly found in commercial driving and okada riding. Out of the 285 participants, $37(13 \%)$ had primary school certificate, $114(40 \%)$ had secondary education, $100(35 \%)$ had NCE/OND (equivalent of a diploma), $11(4 \%)$ had university education while $23(8 \%)$ belonged to 'other unclassified' category. Beside, 69 respondents (24\%) were single, $117(62 \%)$ were married, $27(10 \%)$ were divorced while $4 \%$ were separated. The age range of the participants is $17-69$ with the mean age of 36.18years ( $S D=10.12)$. Their income levels in Nigerian currency, Naira $(N)$, ranged from $N 10,000$ 
to $\mathrm{N} 60,000$ (where $1 €$ is equivalent to $\mathrm{N} 218$ ); with a mean income of $\mathrm{N} 28978.18$ and $(\mathrm{SD}=13679.31$ ). $42(15 \%)$ of the participants are multiple alcohol drinkers while $243(85 \%)$ of them are acclaimed single drinkers; with Beer having the highest drinkers and Opia-pia and Whiskey having the lowest drinkers ( $N=94 ; 9 ; 9$; respectively).

\subsection{Instrument}

The instrument used for data collection was a self-reported and psychometrically robust questionnaire. The questionnaire consisted of five sections: 1) the socio-demographic; 2) the 57 -items Eysenck Personality Questionnaire (EPQ)[27],[28] as a measure of Neuroticism, Extraversion/introversion and Psychoticism Personality traits; 3) the 20-items Self Rating Anxiety Scale; [29] 4) the 20-items selfrating depression scale [29] and 5) the 20 items alcohol dependence scale by [30]. Participants were asked to rate themselves on these measures and their responses were collated for data analysis. The variables examined included depression, anxiety, personality traits (Neuroticism, extraversion/introversion), current age and onset age of drinking.

\subsection{Data analysis}

It was hypothesised that the variables of interest in this study (including the scores of each participant on personality traits, depression, anxiety and drinking factors such as alcohol dependence inventories, onset age of drinking, etc.) will show significant interrelationships. The data collected was subjected to descriptive analysis, chi square, Pearson correlations and independent t-test to examine how the individual psychological characteristics of the participants affected their group and related to their alcohol drinking behaviour. The descriptive analysis revealed the pattern of alcohol drinking among the ORs and CDs.

\subsection{Results}

\subsection{Pattern of alcohol use}

Fig. 1 below presents the emerged pattern, from the descriptive statistics, of the various alcoholic products commonly consumed by the CDs and ORs. The Chi square test was performed to examine how the groups relate in terms of their alcohol consumption. Its outcome showed a significant relationship between the two groups, $\mathrm{CDs}$ and $\mathrm{ORs}\left(\mathrm{X}_{2}(8)=46.17, \mathrm{OR}=55.7 \mathrm{~N}=285 \mathrm{P}<.001\right)$ and their patterns of alcohol consumption. Their frequency of drinking indicate that significantly, more commercial drivers drink unbranded alcohol beverages (e.g. Shepe, Ogogoro, Opa eyin, Opia-pia) than the Okada riders (Figure 1), but more Okada riders were more likely to take mixtures of drinks than the commercial drivers.

\subsection{Correlation analysis and results}

The correlation test was done to explore how the onset age of drinking relates to the psychological variables in the study among the two groups: ORs and CDs. Table 1 below shows how each of the factors examined relates to one another among the CDs and ORs. The inter-correlation showed that the age at the onset of drinking was significantly inversely related to age at the time of data collection, implying that the older the participants were at the time of data collection, the younger they were when they started drinking. The result implies that older driver participants started their drink-driving behaviour at an earlier age than the younger drivers. Only a hundred and forty-two participants $(\mathrm{N}=82$ for $\mathrm{CDs}$ and $\mathrm{N}=60$ for $\mathrm{ORs}$ ) responded to the question on the onset age of drinking. The mean age for the onset of drinking alcohol for the ORs was 19.23 while that of the CDs was 18 . 


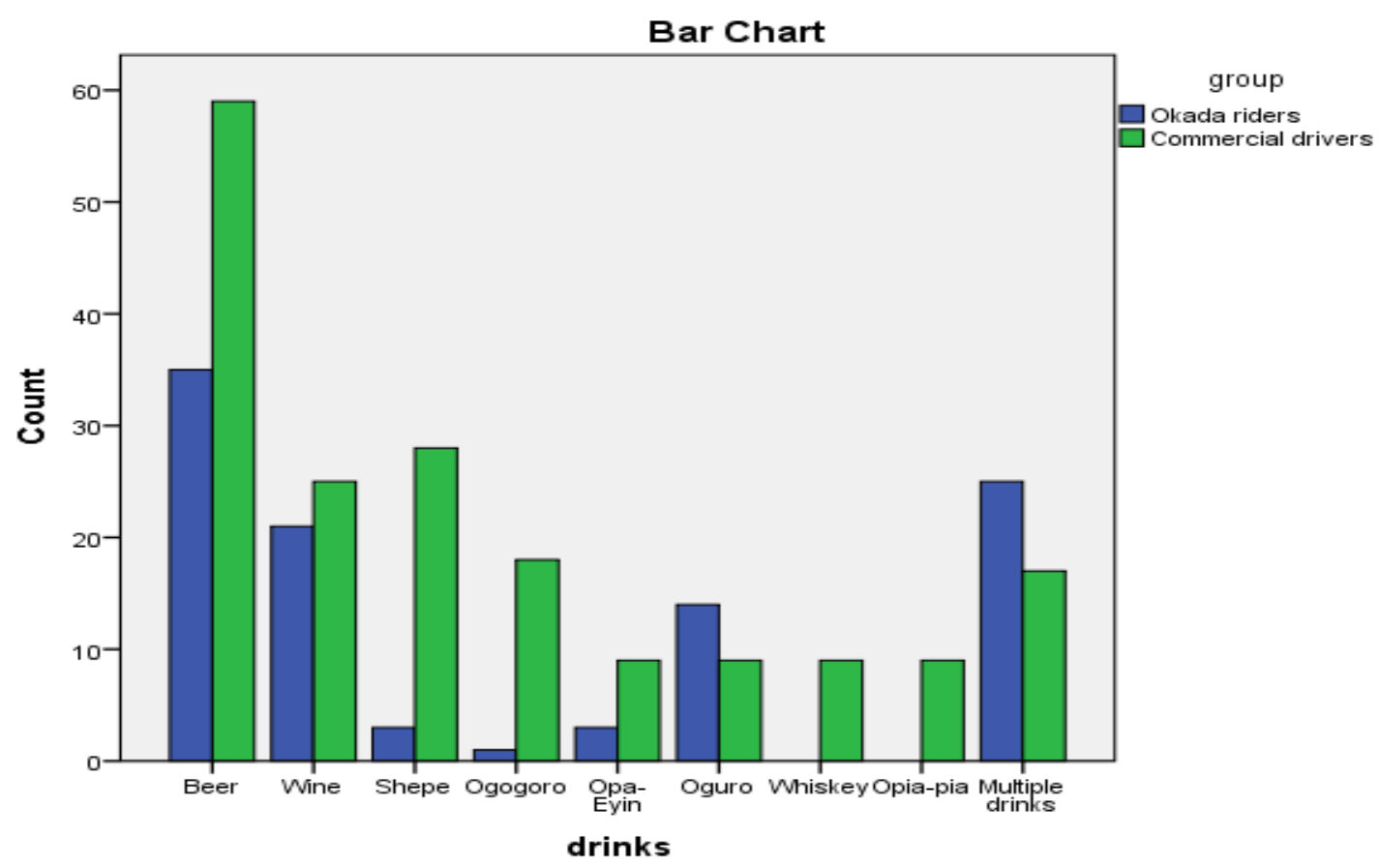

Figure 1 - The pattern of alcohol consumption among the ORs and the CDs

The participants' age at the onset of drinking behaviour was also significantly and inversely correlated with Neuroticism among them $(r=-0.538 ; p<0.01,2$ tailed). The data implied that the younger the age of onset of drinking alcohol, the higher the level of neuroticism reported by the participants.

Table 1: Pearson correlation showing the inter-correlation of the variables examined

\begin{tabular}{|ccccc|}
\hline & Depression & Current age & Neuroticism & Anxiety \\
\hline Onset age of drinking & .080 & $-.226^{* *}$ & $-.538^{* *}$ &.$-.436^{* *}$ \\
\hline Depression & $.184^{* *}$ & $-.191^{* *}$ & .060 \\
\hline Current age & &.-052 & $.192^{* *}$ \\
\hline Neuroticism & & & $.646^{* *}$ \\
\hline
\end{tabular}

Anxiety and the age of the onset of drinking behaviour were significantly and inversely related with each other ( $r=-0.436: p<.01,2$ tailed). This implies that the younger the age of the onset of drinking, the more likely to have higher anxiety among the participants.

There was a significant positive relationship between the age of the participants and their reported depression. It implies that older people were more likely to report greater depression than the younger ones $(r-.184 ; p<.002,2$ tailed).

Although, there was no significant relationship between anxiety and depression, these two disorders were significantly related to neuroticism. However, anxiety and neuroticism were significantly positively correlated among the participants $(r=.646 ; p<.0 .01,2$ tailed). This result indicates that those who scored high on anxiety among the participants also scored high on neuroticism, but those who score 
low on depression scored high on neuroticism. The result has confirmed the prediction formulated from literature that neuroticism may be significantly related to anxiety and depression.

\subsection{The t-test analysis and results}

Table 2 presents the summary of the results of the T-test analysis which was conducted to examine how the CDs and ORs compared with each other on the variables of: onset age of drinking, extraversion-introversion traits, neuroticism traits, anxiety, depression and alcohol dependency.

The T-test results above show that the age when the ORs started drinking alcohol was significant different from that of the CDs. The mean scores show that the commercial drivers started drinking alcohol at a slightly lower age compared to the Okada riders.

The Okada riders' mean score $(32.4 \mathrm{~N}=102)$ was significantly lower on the anxiety scale than the mean score of the Commercial drivers (35.1, $\mathrm{n}=183) ; \mathrm{t}(283)=2.8 ; \mathrm{P}<.01,2$ tailed).

The mean score of Okada riders on the depression scale (49.2; $n=102)$ was significantly higher than that of the commercial drivers $(51.04 ; n=183) ;(t(283)=1.4 ; P<.05,2$ tailed $)$.

The comparison of Neuroticism showed that the Okada riders' mean score $(11.53, n=102)$ was also significantly higher than that of the Commercial drivers: $9.52, n=183 ;(t(283)=3.9 ; P<.001,2$ tailed).

However, no significant differences were observed on the introversion versus extraversion dimension, and the 'lie' scores of the participants.

Table 2: Summary of $t$ test table of analysis showing the comparison of the two groups across the psychological and alcohol drinking variables

\begin{tabular}{|c|c|c|c|c|c|c|c|c|c|}
\hline \multirow[b]{3}{*}{ Variables } & \multicolumn{5}{|c|}{ Groups } & & \multirow{3}{*}{$\begin{array}{c}\mathrm{t} \\
\text { value }\end{array}$} & \multirow{3}{*}{$\begin{array}{c}\mathrm{F} \\
\text { value }\end{array}$} & \multirow{3}{*}{$\begin{array}{c}\mathrm{P} \text { value (Sig. } 2 \\
\text { tailed) }\end{array}$} \\
\hline & \multicolumn{3}{|c|}{ Commercial Drivers } & \multicolumn{3}{|c|}{ Okada riders } & & & \\
\hline & $\mathrm{N}$ & $\begin{array}{l}\text { Mean } \\
\text { Values }\end{array}$ & SD & $\mathrm{N}$ & $\begin{array}{l}\text { Mean } \\
\text { values }\end{array}$ & SD & & & \\
\hline $\begin{array}{c}\text { Onset age of } \\
\text { drinking }\end{array}$ & 82 & 18 & 2.7 & 60 & 19.2 & 3.6 & 2.2 & .005 & .03 \\
\hline Extraversion & 183 & 11.5 & 4.6 & 102 & 10.9 & 3.6 & -1.4 & 18.1 & .20 \\
\hline Neuroticism & 183 & 9.2 & 5.3 & 102 & 11.5 & 3.4 & 3.9 & 31.7 & .001 \\
\hline Lie & 183 & 4.8 & 1.3 & 102 & 4.5 & 1.3 & -1.9 & 0.3 & .06 \\
\hline Anxiety & 183 & 35.1 & 8.4 & 102 & 32.4 & 7.1 & -2.8 & 5.1 & .005 \\
\hline Depression & 183 & 51.0 & 6.2 & 102 & 49.2 & 8.2 & -1.95 & 20.7 & .05 \\
\hline $\begin{array}{c}\text { Alcohol } \\
\text { dependence }\end{array}$ & 183 & 5.1 & 4.7 & 102 & 3.5 & 4.1 & -3.9 & 12.1 & .001 \\
\hline
\end{tabular}

\subsection{Discussions}

The results from this study showed that both the ORs and CDs are still actively engaging in drinkdriving behaviours (Figure 1). This is not different from [9] who reported how $67.2 \%$ of the drivers they interviewed admitted to alcohol drinking and driving. It is not surprising that the study further showed that both the ORs and the CDs were consuming branded and unbranded alcohol products. This is because researchers have previously noted how various alcohol products are sold to the CDs and ORs across various garages in Nigeria in the form of herbal mixtures [31],[8], [10], [32]. Unfortunately, previous studies have reported on the weakness of the enforcement of the Blood Alcohol Concentration test in Nigeria [9]. This is compounded by the scanty availability of Breathalysers to check the amount of alcohol concentration in drivers while driving [33], [9]. 
The older drivers reported higher depression than the younger ones (Table 1), which might indicate the presence of early life depressive symptoms as observed in a previous research among adolescents [26]; wherein adolescents who had medium to high levels of depressive symptoms were twice likely to use alcohol. Surprisingly, no significant relationship was observed between reported depression and anxiety among the ORs and CDs whereas, lower neuroticism was observed which related to increased depression and high anxiety. The insignificance of the relationship between anxiety and depression will appear contrary to some previous reports [14], [15] [16], but lends support to studies that could not connect these two psychological factors [17], [18].

The sample studied showed a significant relationship between depression and neuroticism, but not with anxiety. This points to the trait of emotional instability (neuroticism) and might indicate the presence of depression and/or anxiety among those sampled; thus showing what needs to be targeted in the design of psychological interventions for the ORs and CDs.

The CDs scored significantly higher on neuroticism, anxiety, depression and alcohol dependency scales than the ORs. They also started alcohol drinking behaviour slightly earlier than the ORs but their mean age of 18 years implies that they started drinking toward their late adolescence. It might not be surprising then that they are still actively engaged in alcohol drinking as they scored higher on the alcohol dependency scale. A previous study [25] indicated that the onset of drinking at an adolescent age was a risk factor for continuous alcohol drinking and alcohol dependency problems in adulthood. It is not very clear in this study whether lie scores of the participants requires further interpretation. However, such could be explored in a future study since no significant difference was observed for this factor among the CDs and ORs.

\subsection{Conclusions}

The results from this study have shown that there are inherent psychological and social factors that could relate with alcohol drink-driving problems among the CDs and ORs to influence their road safety consciousness and thus increase the risk of accidents. These factors require specific considerations in the design of which intervention will work for which group of road users. Just as previous studies have suggested that mood disorders and certain personality traits were plausible factors in the increase of accident risks for some individuals, it might be worthwhile to examine the depression and anxiety factors established in the current study in a larger sample among the road users in Nigeria, to see whether a significant pathway to crash/accident prevention is possible. Since depression and anxiety are mood/affective disorders and their symptoms were established in the study, it might be that addressing these factors will enhance road safety and reduce alcohol drinking among the CDs and ORs.

\subsubsection{Implications for research}

Users play a crucial role in sustaining public facilities. In the context of our research, the CDs and ORs contribute to road damage through accidents that are caused by their unwarranted behaviours. Their behaviours also impact on the safety of the passengers whom they transport. Users' behaviour is flagging-up as a potential consideration in human endeavours, especially road provision and usage. The discipline of psychology can help road providers (often the government) to make road usage safer to both drivers and passengers. For example, research can inform the establishment of thresholds of drink limits that are allowable to drivers and riders. Governments can also design and implement upstream solutions to prevent drink-driving while research can test the impact $s$ of these. 


\subsubsection{Implications for pedagogy}

The learning of behavioural issues in psychology, business, marketing and management science is relatively high compared with its treatment in core technical disciplines. Collaboration between behaviourally-inclined and technically-inclined disciplines will minimise certain human misdemeanours in practices in the later sector. It is in this respect that the writers of this article have launched their PsyCon (Psychology in Construction) initiative, which will strengthen the synergy between psychology and the built environment and open new frontiers for multi-disciplinary research and explore avenues for enhancing pedagogy, albeit through research-informed curriculum development. It is for example possible for drunk-driving behaviours to influence traffic management systems. Hence a synergy exists between research and pedagogy and psychology and the built environment. The poster display on the Psycon initiative explores these possibilities further.

\subsubsection{Limitation of study and recommendations for a wider research}

The sample size employed in this study might not be representative of the Nigerian CDs and ORs. As the study was conducted in only lbadan city, a nationwide study which will examine the psychological factors among a wider sample is therefore suggested. Moreover, self-report measures may not accurately identify individuals who have disorder from those who only have traits; a more comprehensive psychosocial screening is thus suggested for future research. It might be that this will prevent/reduce the risk of accidents among the drivers.

\section{REFERENCES}

1. Gopalakrishnan, S. (2012). A public health perspective of road traffic accidents. Journal of Family Medicine Primary Care, 1(2), pp. 144-50.Available on http://www.ncbi.nlm.nih.gov/pmc/articles/PMC3893966/ [accessed 08 January 2016]

2. Nantulya, V.M. and Reich M.R. (2002). The Neglected Epidemic: Road Traffic Injuries in Developing Countries. British Medical Journal. 324, pp. 1139-1141. Available from: www.bmj.com/content/324/7346/1139.]. [accessed 08 January 2016]

3. Ameratunga, S., Hjah, Ni, Norton, R. (2011). Confronting Disparities to Address Global-Health Problems. Lancet. 367, pp. 1533-1540.

4. World Health Organization (2009). Global Status Report on Road Safety: Time for Action. Geneva: who. Retrieved from www.who.int/violence injury prevention/road safety status/2009 [Accessed on 18 July 2015].

5. World Health Organization, (2004). World Report on Road Traffic Injury Prevention. Geneva: WHO. Available at http://www.who.int/violence injury prevention/publications/road traffic/world report/en/index. html [Accessed on 20 August 2014]

6. Wiston, F.K. and Jacobsohn, L. (2010) .A practical approach for applying best practices in behavioural interventions to injury prevention. Injury Prevention 16(2), pp. 107-112.

7. Trifiletti L.B., Gielen A.C., Sleet D.A., and Hopkins, K. (2005). Behavioral and social sciences theories and models: are they used in unintentional injury prevention research? Health Education Research 20, pp. 298-307.

8. Dumbill, E. (2013). Changing Patterns of Alcohol Consumption in Nigeria: An Exploration of Responsible Factors and Consequences. Medical Sociology online, 7(1), pp. 20-33. Retrieved from http://www.medicalsociologyonline.org/resources/Vol7lss1/7.1-Changing-

Patterns_Dumbilli.pdf (Accessed 18 July 2015) 
9. Ogazi, C and Edison, E (2012). The Drink Driving Situation in Nigeria. Traffic Injury Prevention,_13(2).pp. 115-119.

10. Kehinde, O. S., and Olusegun, F. F. (2012). Taking Alcohol by Deception II: Paraga (Alcoholic Herbal Mixture) Use Among Commercial Motor Drivers in a South-Western Nigerian City. BioMedical Central Research Notes, 5, pp. 301. doi: 10.1186/1756-0500-5-301 Retrieved from http://www.ncbi.nlm.nih.gov/pmc/articles/PMC3485188/ (18 January 2016)

11. Onifade ,C.A, Aduradola, R.R., AND Amoo, S.O. (2012). The Effect of Socio-Economic Survival of Okada Riders on African Cultural Values. Global Journal of Human Social Sciences, Art and Humanities, 12(14), pp. 45-52.

12. Hickman J. (2013) Work Related Distress and Mental Disorders in Commercial Motor Vehicle Drivers. ANB70 Research problem statement 17. Retrieved from http://rns.trb.org/dproject.asp?n=35530. (15 April 2015

13. Williams J, Tregear S., and Amana A. (2011). Psychiatric Disorders and Driver safety: A systematic review. Proceedings of the sixth international driving symposium on Human factors in drivers assessment, training and Vehicle Design. Pp284-290. Retrieved from http://drivingassessment.uiowa.edu/sites/default/files/DA2011/Papers/041 WilliamsTregear.pd f [Accessed on 13 January 2016]

14. Roth, M., Gurney, C., AND Kerr, G.T. (1972). Studies in the Classification of Affective Disorders: The Relationship Between Anxiety States and Depressive Illness-I. British Journal of Psychiatry, 121, pp. 147- 161.

15. Lecrubier Y. (2001). The Burden of Depression and Anxiety in General Medicine. Journal of Clinical Psychiatry, 62(Suppl 8): pp. 4-9.

16. Garber, J. and Weersing, V.R. (2010) Comorbidity of Anxiety and Depression in Youth: Implications for Treatment and Prevention. Clinical Psychology (New York), 17(4), pp. 293306.

17. Silverstone, P, H. and Studnitz, E. (2003). Defining Anxious Depression: Going Beyond Comorbidity. Canadian Journal of Psychiatry, 48(10), pp.675-680.

18. Andrews, G., Hobbs, M.J., Borkovec, T.D., Beesdo, K., Craske, M.G., Heimberg, R.G., Rapee, R.M., Ruscio, A.M., and Stanley, M.A. (2010). Generalized Worry Disorder: A Review Of DSM-IV Generalized Anxiety Disorder And Options For DSM-V. Depression and Anxiety, $\mathrm{X}(\mathrm{Y})$, pp. 1-14. Retrieved from http://www.dsm5.org/Research/Documents/Andrews\%20et\%20al Generalized\%20Worry\%20 Disorder.pdf [19 January, 2016].

19. Zerbe, W.J, and Daulhus, D., (1987). Socially desirable responding in organisational behaviour: A Reconception. Academy of Management 12(2). 250-264. doi: 10.5465/AMR.1987.4307820. Accessed from http://amr.aom.org/content/12/2/250.short [10 January, 2016]

20. Smith, G.M. (2009) Personality and smoking: A review of the empirical literature . In Hunt, W.A and Hunt, W. Learning mechanism in smoking. Pp 42-57 Accessed from https://books. google.co.uk/books?hl=en\&lr=\&id=9xwCbL53YW8C\&oi=fnd\&pg=PA42\&dq=eyse nck+personality+questionnaire+has+been+used+variously+in+empirical+studies\&ots=SgUuA KnWI \&sig=W7r8ImD5cTo49c4uvNWTYhTCtNg [18 January 2016]

21. McCrae, R. R., \& Costa, P. T. (1983). Social desirability scales: more substance than style. Journal of Consulting and Clinical Psychology, 51, pp. 882-888. 
22. Brown, M. S., \& Kodadek, S. M.(1987). The use of the lie scale in psychometric measures of children. Research in Nursing and Health, 10(2), pp. 87-92.

23. Birenbaum, M., \& Montag, J. (1989). Style and substance in social desirability scales. European Journal of Personality, 3, pp. 47-59.

24. Granleese, J., \& Barrett, T. F. (1990). The social and personality characteristics of the Irish chartered accountant. Personality and Individual Differences, 11, pp. 957- 964.

25. McCambridge, J., McAlaney, J and Rowe, R. (2011). Adult Consequences of Late Adolescent Alcohol Consumption: A Systematic Review of Cohort Studies. PloS Medical 8(2):e1000413. Available online at http://www.ncbi.nlm.nih.gov/pubmed/21346802 [Accessed on 10 January 2016]

26. Wu, P., Bird, H.R., Liu, X., Fan, B., Fuller, C., Shen, S., Duarte, C.S and Canino, G.J. (2006). Childhood Depressive Symptoms and Early Onset of Alcohol Use. Pediatrics.118(5): pp. 1907-1915

27. Eysenck, H.J. and Eysenck S.B.G. (1963). Eysenck Personality Inventory. San Diego: Educational and Industrial Testing Service.

28. Eysenck, H.J. and Eysenck S.B.G. (1964). Manual of the Eysenck Personality Inventory: London: University of London Press.

29. Zung W.W.K. (1974). The Measurement of Affects: Depression and Anxiety. In P. Pinchot (Ed), Psychological Measurements in Psychopharmacology (Modern Problems in Pharmacopsychiatry Series, vol. 7). Paris: Karger

30. Helzer, J.E., Bucholz, K., and Robins, L.N. (1992) Five Communities in the United States: Results of the Epidemiologic Catchment Area Survey. In: Helzer, J.E., and Canino, G.J., (eds). Alcoholism in North America, Europe, and Asia. New York: Oxford University Press; pp. 71-95.

31. Animashaun, R.A. and Animasahun, V.O. (2014). Predisposing Influence of Home Factors, Negative Self-Components and Peer Orientation on Substance Abuse among Okada Riders in Ibadan. British Journal of Applied Sciences and technology 4(9), pp. 1320-1333.

32. Makanjuola B.A, Oyeleke, S.A. and Akande T.M. (2007). Psychoactive Substance Use among Long Distance Vehicle Drivers in Ilorin Nigeria. Nigerian Journal of Psychiatry 5(1), pp. 14-18.

33. Peltzer, K and Peqpid, S. (2015). Drinking and Driving Among University Students in 22 Low, Middle Income and Emerging Economy Centres. Iran Journal of Public Health. 44(10), pp. $1330-1338$ 